\title{
Short stature and chronic renal failure: what concerns children and parents?
}

\author{
J M Reynolds, A J Wood, D M Eminson, R J Postlethwaite
}

\begin{abstract}
Multicentre trials are evaluating growth hormone treatment in short children (height $>2$ SDs below mean) with chronic renal failure (CRF), on dialysis, or with a transplant. Thirty children and parents from four centres were interviewed to assess psychological functioning and evaluate their concerns about growth in the context of CRF. There were 24 males and six females, age range 2-18 years. Fifty per cent of patients had additional non-renal complications and $30 \%$ had learning difficulties.

Differences between the respective concerns of parents and children were striking. Parents' predominant concern was their child's future health $(50 \%)$ and prospects $(37 \%)$ while children's main concern was the impact of illness on their family (50\%). Growth was a major concern for $30 \%$ of parents and $28 \%$ of children.
\end{abstract}

Growth problems are important and should be considered within the context of other illness issues. Improved understanding of parental and child concerns may help maximise the benefits of growth hormone and assist in the management of children with CRF.

(Arch Dis Child 1995; 73: 36-42)

Keywords: growth hormone, renal failure, short stature.

Among the many complications of chronic renal failure (CRF) and its treatment today, relative short stature is well established as a problem in children and adolescents. ${ }^{12}$ In addition, one consequence of the increased availability of treatment for infants and very young children with CRF is that extreme short stature is now commonplace in paediatric nephrology clinics. Several studies of children with CRF have highlighted growth delay as an area of major importance, hindering social adjustment. ${ }^{34}$ Previous work in our department has not found growth to affect overall long term social or psychological adjustment of young adult dialysis and transplant patients, 56 but clinical impressions suggest that poor growth is a cause for concern during childhood and that a few individuals experience considerable problems in relation to growth and appearance. ${ }^{78}$

For children with CRF, growth is one of many problems relating to their chronic illness and its treatment. It is not clear how concern about growth may be evaluated by patients or parents, in the context of many other worries about the illness and its outcome. A number of studies have examined the concerns of children with chronic illness and found that these may include anxieties relating to specific aspects of treatment, such as injections in children with diabetes, but may also encompass more general concerns about restrictions in school or social life and worries about the future. ${ }^{9}$ Concerns are likely to vary over time and, in particular, may alter with the age of the child as well as the stage and severity of illness. ${ }^{10}$

Psychological and social consequences of both short stature and CRF have been described. Law ${ }^{11}$ and Gordon et al ${ }^{12}$ have studied the psychological consequences of short stature of varying aetiology in children. They reported variable problems depending on the cause of growth delay, and outlined difficulties in peer relationships, self esteem, and school attainment. Other studies have not found that a simple relationship exists between short stature and disturbed psychological functioning, but have found that other difficulties such as social disadvantage and cognitive deficits may mediate the relationships. ${ }^{13} 14$ Garralda et al described differences in psychological adjustment between a group of children with CRF and normal controls. ${ }^{15}$ These differences were related to the severity of renal failure; mood disturbances, low self esteem, and loneliness were more common in the ill group. Those children with both CRF and short stature may therefore be particularly vulnerable to difficulties in psychological and social adjustment.

Growth hormone is now an accepted treatment for short stature caused by growth hormone deficiency but is also used in patients with delayed growth resulting from other causes, including genetic or chromosomal abnormalities, as well as in chronic disease. Several studies have examined the effects of growth hormone treatment on the psychological and social adjustment of patients but varied results are reported. ${ }^{16-18}$ Boulton et al studied 66 children with significant short stature during two years of growth hormone treatment and identified differences between parents and their children, in their perceptions of the consequences of short stature. 16 Rotnem et al reported ambivalence about growth hormone treatment, particularly among older children who had anxieties about the way in which others would react to the changes in their physical appearance. ${ }^{17}$ In spite of accelerated growth, children and parents perceived the treatment to be a failure relative to their expectations and an increase in depressive features was reported among the children. 
Table 1 Subjects and treatment centres

\begin{tabular}{lcllll}
\hline No of patients & Total & Manchester & Leeds & Birmingham & London \\
\hline In Kabi trial & 64 & 14 & 6 & 19 & 25 \\
Psychosocial study & 30 & 16 & 4 & 5 & 5 \\
$\quad$ Receiving growth hormone & 28 & 14 & 4 & 5 & 5 \\
$\quad$ Refused growth hormone & 2 & 2 & 0 & 0 & 0 \\
Treatment status & 8 & 4 & 1 & 1 & 2 \\
$\quad$ Predialysis & 14 & 6 & 3 & 4 & 1 \\
$\quad$ Dialysis & 8 & 6 & 0 & 0 & 2 \\
Transplant & & & & & \\
\hline
\end{tabular}

We are unaware of any studies to date which have examined the psychological impact of growth hormone treatment on children with CRF. The present study was developed to run in parallel with a trial of the effectiveness of growth hormone treatment. The trial gave rise to some questions; first about the existing level of parental and child concern about the child's growth problems and second, whether discussions at the time of entering the trial or subsequently during the course of treatment would heighten any pre-existing concerns about short stature. In other words, would matters be made worse by raising the issue for discussion? The study was designed in two parts to address these questions: (1) A cross sectional study of the concerns of parents and children with CRF and significant short stature; their psychiatric adjustment and their understanding of complex medical issues about whether to accept treatment. (2) A longitudinal study which will assess the impact of growth hormone treatment on child and parental psychosocial functioning during the next two years. The present paper describes the baseline psychological functioning of parents and children and outlines their level of concerns about growth in the context of CRF at the outset of treatment. Issues connected with recruitment, information giving, and decision making about the trial are reported separately. ${ }^{19}$

\section{Subjects and methods}

GROWTH HORMONE TRIALS

These are a series of multicentre studies, funded by Kabi Pharmacia, of the effectiveness of somatropin treatment (1 unit $/ \mathrm{kg} /$ week) in predialysis, dialysis, and post-transplant patients with significant short stature. Criteria for entry to the trials were height $>2$ SD below mean for age, and/or growth velocity $<25 \%$ for age and in the predialysis study glomerular filtration rate $<50 \mathrm{ml} / \mathrm{min} / 1 \cdot 73 \mathrm{~m}^{2}$. Transplant patients were randomly allocated to start growth hormone treatment in either the first or second year. All other patients receive growth hormone from the outset for a period of one year. A total of 115 patients were recruited to the trial from 12 centres in the UK between 1991 and 1993. Patients for the psychosocial

Table 2 Age and treatment status of subjects

\begin{tabular}{llll}
\hline & \multicolumn{2}{l}{ Age (years) } & \\
\cline { 2 - 4 } Treatment status & $0-4(n=7)$ & $5-10(n=10)$ & $11-18(n=13)$ \\
\hline Predialysis & 3 & 5 & 0 \\
Dialysis & 4 & 4 & 6 \\
Transplant & 0 & 1 & 7
\end{tabular}

study were recruited sequentially from four of the centres between November 1991 and November 1992.

PATIENT GROUP

Seventeen patients attending the Royal Manchester Children's Hospital fulfilled criteria for entry into the Kabi trials and all were invited to take part in the psychosocial study. In order to increase the sample size patients were also recruited from three other centres who were participating in the trials. All patients from St James's Hospital, Leeds $(n=4)$ and the Royal Free Hospital, London $(n=6)$ allocated to the Kabi trial after January 1992 were invited and all patients on dialysis from Birmingham Children's Hospital $(n=5)$. Table 1 shows the distribution of patients between centres and treatment regimens. A total of 30 patients agreed to take part in the psychosocial study, of whom two had refused growth hormone treatment. During the recruitment period two other patients were eligible: one refused both the growth hormone trial and the psychosocial study and the other was excluded because of language difficulties.

Table 2 shows the distribution of patients by age and treatment regimen; $24(80 \%)$ were male and six (20\%) were female. Age ranged from $2-18$ years (mean $9 \cdot 2$ years).

\section{PROCEDURES AND INSTRUMENTS USED}

Parents and patients were initially given an explanation of the growth hormone trials in the context of a standardised interview. ${ }^{19}$ Consent for the psychosocial study was sought by the paediatrician conducting this interview, regardless of whether consent for the growth hormone trial was given. Paediatricians also completed a questionnaire for each patient giving details of their renal condition, including severity and treatment and details of any other medical problems.

\section{Psychosocial interviews}

Parents and children aged 4 years and over were interviewed separately at each centre as soon as possible after their pretreatment clinical interview with the paediatrician. Most interviews took place before growth hormone treatment had commenced.

\section{Parent interviews}

A standardised semistructured interview was administered to all parents. The same interviewer (JMR) conducted all interviews in two centres $(n=18)$, and also trained interviewers in the remaining centres. Information was collected in the following areas:

(1) Baseline sociodemographic data and details of parental and child health and psychosocial functioning;

(2) Parental assessment of their child's adjustment and behaviour, type of schooling and educational progress, and the child's friendships and activities. 
(3) Evaluation and rating of 'concerns' relating to the child's illness or treatment. We compiled a list of 11 areas of possible concern which were identified from previous studies. ${ }^{20}$ These were: current general health; having $\mathrm{CRF}$ /being on dialysis/having a transplant (as applicable to individual patients); treatment at home (other than dialysis) - for example, diet, tablets and medication, fluid restriction; growth; appearance; coming to hospital; child's behaviour and emotions; schooling and friends; effects of the kidney disease on the family; future health and prognosis; general prospects for the future.

(i) Rating - Each concern was shown to parents on a card and they were engaged in a discussion about that area and asked to rate it on a three point scale for their 'current concern': $0=$ no current concern about this issue; $1=$ some $/$ minor concern; $2=\mathrm{a}$ lot $/ \mathrm{major}$ concern. A concern was rated as 'major' if it involved a level of intensity and frequency leading to daily preoccupation or worry. A 'minor' rating applied to a more transient or background concern, occurring less often than once a day. Potential areas of overlap were clarified by the interviewer to allow the categories to distinguish reliably between different areas of concern.

(ii) Ranking - After rating concern for each area, parents were asked to rank all concerns against each other - that is, to give a list in order of seriousness.

(iii) Child's concerns - Parents were also asked to describe and rank their perceptions of their child's concerns.

(4) Standardised questionnaires - were administered. The general health questionnaire $^{21}$ was used to assess current parental mental distress. Children's behaviour was assessed by the Rutter A questionnaire ${ }^{22}$ for children aged 7 years and over, and the behaviour checklist ${ }^{23}$ for children $<7$ years.

\section{Child interviews}

All children of 4 years and over were interviewed individually in each centre. In two centres, interviews $(n=18)$ were conducted by a child psychiatrist (AJW), who trained colleagues in the other centres. The interviews were semistructured, in parallel with parental interviews, and included the following:

(1) The friendships interview was used to establish availability, intimacy, and adequacy of current peer relationships. ${ }^{24}$

(2) Evaluation and rating of concern about illness and treatment. This was conducted in the same way as for the parental interview but the list of concerns was reduced to nine areas, by excluding behaviour and emotions and combining prognosis and general future prospects into one category - that is, concern about the future. For the younger children pictorial representations of the areas of concern were used. Where possible a rating and ranking of the child's concerns, and the child's perception of his/her parent's concerns were recorded.

(3) Children of 7 years and over completed standardised questionnaire measures of: self esteem (Harter perceived self competence scales) ${ }^{25}$; depressive symptoms (mood and feelings questionnaire $)^{2627}$; and current mental distress (general health questionnaire) ${ }^{21}$ for patients aged 17 and over.

(4) Mental state examination: a checklist of psychiatric signs and symptoms was completed in order to establish the presence or absence of psychiatric disorder. Developmental and learning difficulties were recorded.

\section{Analysis}

Data analysis was carried out using the SPSSpc programme. Descriptive statistical tests were used as appropriate ( $\chi^{2}$ or Fisher's exact test, Spearman's rank correlations, and MannWhitney U tests).

\section{Results}

PHYSICAL CHARACTERISTICS OF PATIENTS Height

This patient group has extreme short stature. Four $(13 \%)$ were 2 SDs below expected height, $10(33 \%)$ were 3 SDs below, and 16 $(54 \%)$ were 4 SDs below expected height. Transplant patients were significantly shorter than the other treatment groups; $87 \%$ were three or more SDs below the norm $\left(x^{2}=6 \cdot 4\right.$, ldf, $p<0.01)$. Twenty five $(83 \%)$ of the group were prepubertal and the other five had entered puberty.

\section{Renal replacement treatment}

Mean age at start of renal replacement treatment was 6.5 years with nine $(30 \%)$ children beginning the treatment before the age of 5 years. Table 2 shows the distribution between four treatment categories; seven patients were on continuous cycling or continuous ambulatory peritoneal dialysis and seven were on haemodialysis.

\section{Current medical status}

Half of the group had additional non-renal physical disorders such as multiple congenital abnormalities, including two patients with VATER syndrome. Other diagnoses included bilateral optic nerve infarction; impaired hearing; epilepsy $(n=2)$; microcephaly $(n=2)$; severe learning difficulties with hyperactivity; developmental delay and hypertonia; mild asthma. At the time of the pretreatment clinical interview, $50 \%$ of the group were described as in 'good health' by paediatricians with $12(40 \%)$ having 'minor problems', such as hypertension and bilateral hernias. Three $(10 \%)$ patients had 'major problems': severe uncontrolled bone disease, urethral fistula and bowel problems, causing incontinence and diarrhoea. Seven $(23 \%)$ children had had two or more recent admissions to hospital.

\section{DEMOGRAPHIC DATA}

At least one parent, the main caregiver, of each child was interviewed. In most cases this was the 


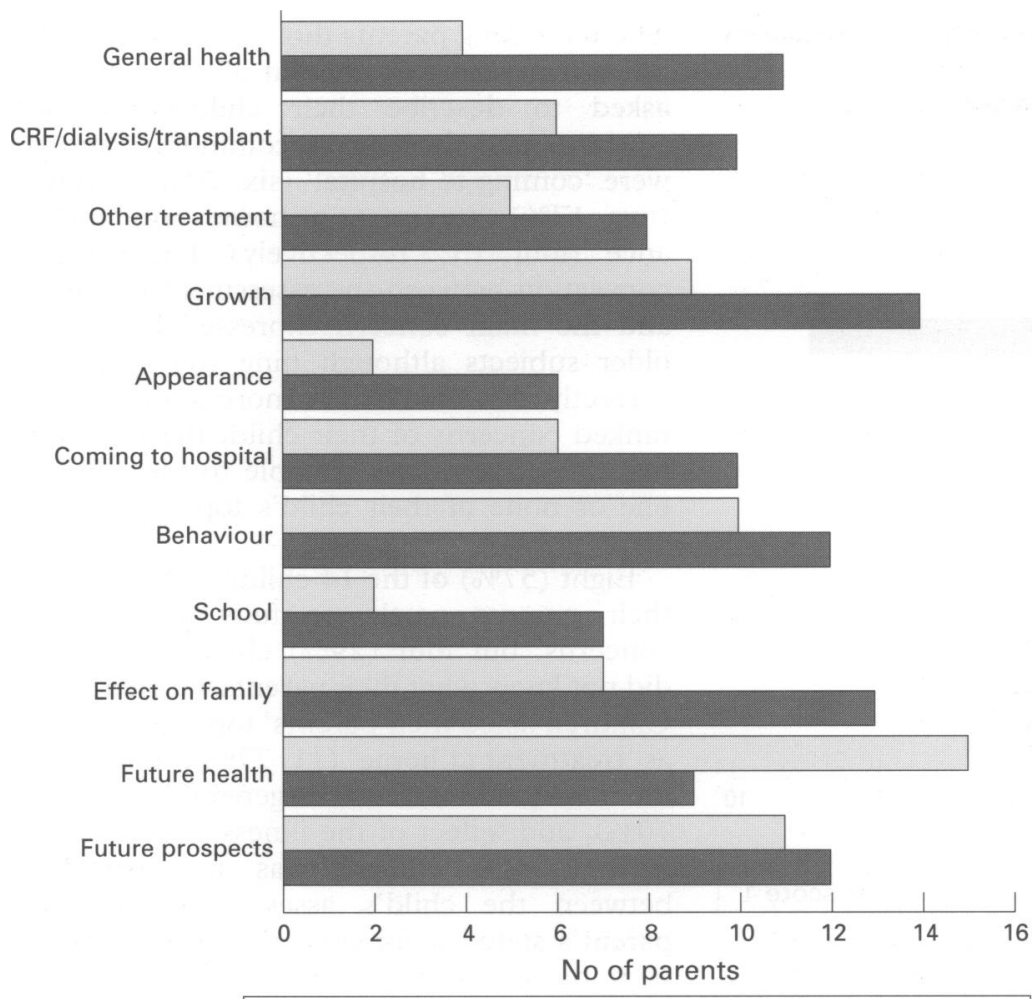

Major concerns score 2 Minor concerns score 1

Figure 1 Parental scores for areas of major and minor concern $(n=30)$.

mother but fathers were the main informants in five $(17 \%)$ cases. One child was living with a foster mother and a married sister involved with the care of another patient was interviewed because of parental language difficulty. Two subjects were from the same family. Nine $(29 \%)$ children were from single parent households and $23 \%$ of parents were unemployed. Five of 28 (18\%) parents scored $>5$ on the general health questionnaire, indicating a significant level of current mental distress.

\section{CHILD'S BEHAVIOUR AND ADJUSTMENT \\ Parental reports}

At interview, parents reported that half the group had some emotional or behaviour problem, of which five $(17 \%)$ were considered severe. Results from the behaviour questionnaires were in close agreement with parental reports. Nine $(30 \%)$ of children, all over 7 years, scored above the cut off for behavioural difficulties. Nine $(30 \%)$ of children had identifiable learning difficulties, defined by attendance at schools for those with learning disabilities, or by a statement of special educational needs (beyond physical handicap requirements alone). This group included a 15 year old boy with severe mental handicap and associated behaviour problems and two brothers with Laurence-Moon-Biedl syndrome, one of whom had severe social relating difficulties. These were among the $11(37 \%)$ children reported by parents to have some problem in relationships. Over one third of school aged children were reported not to have a special friend.

\section{Child reports}

Fourteen ( $47 \%$ ) children were able to complete all parts of the interview and the questionnaires. Those unable to complete all sections were the younger children or those who were unable to participate fully because of learning disability. The ages of those children who completed the child assessment ranged from 9-18 years (mean 13 years).

Five children reported unsatisfactory friendships, all of whose parents had also reported difficulties in peer relationships. Mean scores for the group on the Harter perceived self competence scale were within the range of norms for healthy Scottish schoolchildren, aged 11-15 years. ${ }^{28} \mathrm{~A}$ high level of depressive symptoms was not reported; one child scored above the cut off score on the moods and feelings questionnaire and was also rated as objectively depressed by the interviewer on the mental state examination.

\section{PARENTAL CONCERNS}

Figure 1 shows the 'major' (score 2) and 'minor' (score 1) scores given by parents for areas of concern and demonstrates the varied nature of worries connected with the child's illness. Future health was the most frequently scored concern. It was a major worry (score 2) for half the parents and a lesser concern (score 1) for a further nine $(30 \%)$. Future prospects and child's behaviour were major concerns for $37 \%$ and $33 \%$ respectively. Growth was rated as a concern by a total of $23(77 \%)$ parents (score 1 or 2 ), of whom nine (30\%) scored it as a major concern and $14(47 \%)$ as a minor, less preoccupying worry.

\section{RANKING OF CONCERNS}

Parents' ranking of the 11 areas of concern reflected the trend found in scoring individual items. There was some consensus about the highest ranking items: $60 \%$ of parents ranked 'future health', 50\% ranked 'future prospects', $46 \%$ ranked 'effects on the family', and $43 \%$ ranked 'growth' within their top four concerns. Other items received more varied levels of ranking. Those ranked least frequently among the top four included 'schooling and friends' $(19 \%)$ and 'appearance' (14\%).

\section{CHILD CONCERNS}

Table 3 shows the number of children in each age group who were able to undertake the scoring and ranking of concerns and complete the questionnaires, thereby completing the full

Table 3 Age and competence of subjects to complete interviews; figures are number $(\%)$

\begin{tabular}{lllr}
\hline \multicolumn{4}{l}{ Age (years) } \\
\cline { 2 - 4 } & $\begin{array}{l}0-4 \\
(n=7)\end{array}$ & $\begin{array}{l}5-10 \\
(n=10)\end{array}$ & $\begin{array}{c}11-18 \\
(n=13)\end{array}$ \\
\hline Ability to complete interview & $1(14)$ & $6(60)$ & $12(92)$ \\
Scoring concerns & 0 & $3(30)$ & $12(92)$ \\
Ranking concerns & 0 & $2(20)$ & $12(92)$ \\
All sections & $1(14)$ & $5(50)$ & $2(15)$ \\
Learning difficulties & & & \\
\hline
\end{tabular}




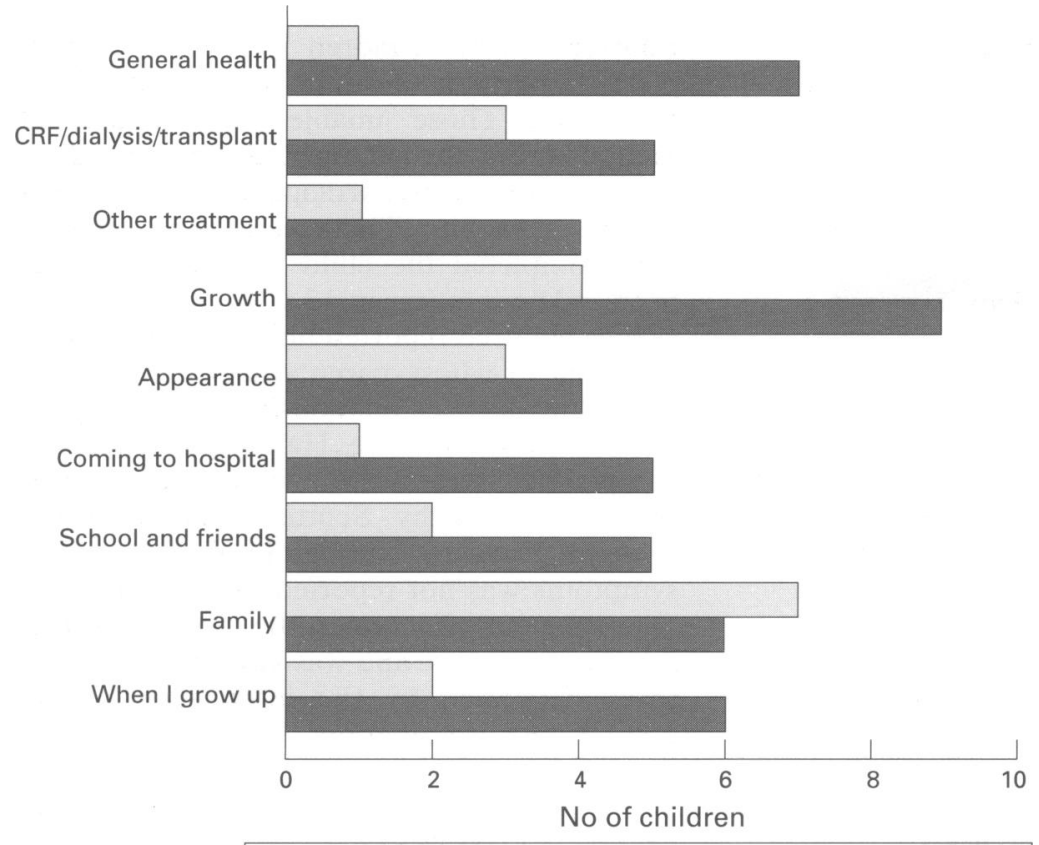

Major concerns score $2 \square$ Minor concerns score 1

Figure 2 Children's scores for areas of major and minor concern $(n=14)$.

interview. Children's abilities to complete all parts of the interview were affected by their cognitive disabilities. There were 11 children who could not complete the scoring and ranking of concerns. All children over the age of 3 years except three children with marked learning difficulties could, however, be engaged in discussion about some aspect of their illness and treatment using the pictorial representations of the concerns. These small children understood, and readily expressed their feelings about treatments (injections, tablets, dialysis and diet) and hospital visits. Few of them were able to use the concepts of growth, appearance, the future, effects of illness on family, or their feeling of general health in a reliable and replicable way. Only two children in the 5-10 year age group could complete al aspects of the interview, although a further four were able to score their level of concern about individual items.

Figure 2 shows the 'major' and 'minor' scores for concerns of the 14 children who were able to complete both the scoring and ranking of concerns. A total of $13(93 \%)$ children rated growth as a concern (score 1 or 2) of whom four $(28 \%)$ scored it as a major, preoccupying concern and nine (64\%) reported minor, less intense worry. Impact of the illness on the family was the most commonly reported area of major concern, given a score of 2 by half of this group, with a further six $(43 \%)$ reporting it as a minor concern. This trend was also reflected in the children's ranking of concerns, with $71 \%$ ranking 'effect my illness has on my family'; 'growth'; and 'general health' in their top four concerns.

PARENT CHILD AGREEMENT

Altogether $46 \%$ of parents said they thought they shared the same concerns as their child.
The remaining parents thought their child had different worries or none at all. Parents were asked to describe their child's top four concerns and those most commonly reported were 'coming to hospital' (six, 20\%), 'growth' (five, $17 \%$ ), 'treatment at home' and 'appearance' (four, $13 \%$ respectively). There was no correlation between the assessment of parents and the main concern expressed by the 14 , older subjects although nine $(64 \%)$ parents correctly identified two or more of the top four ranked concerns of their child; the remaining five $(36 \%)$ parents were able to identify only one or none of their child's top ranked concerns.

Eight $(57 \%)$ of the 14 children thought that their parents partly or fully shared their concerns, but four $(29 \%)$ children said they did not know what their parents worried about. Children listed their parents' top four concerns as 'treatment at home' $(11,77 \%)$, 'renal treatment' $(11,77 \%)$, 'current general health' ( 10 , $70 \%$ ), and 'effect of the illness on the family' (seven, 49\%). There was no correlation between the child's assessment and their parent's stated main concern. Agreement was poor between the child's perception of their parents' top ranked concerns and those stated. Only six $(43 \%)$ children correctly identified two or more from their parents' top four ranked concerns; the majority (eight, 57\%) identified only one of the stated top ranked concerns.

\section{GROWTH}

From the parental and child expressed concerns, we looked for possible associations between concern about growth and physical factors. We found no association between parental concern about child's growth and child's height, age, sex, or renal status. Parental concern about growth was not correlated with the child's concern about growth. Children's concern about growth was significantly correlated with increasing age $(r=0.62, \mathrm{p}=0.001)$ but not with height, sex, or renal status.

\section{GROWTH HORMONE REFUSERS}

Of the two patients who did not receive growth hormone treatment, one was a 2 year old boy with CRF and the other a 12 year old girl with a functioning transplant. The parents decided not to enter their children into the growth hormone trials after the initial, explanatory interview. Poor growth was reported as a minor concern by the parents of both children, and in the case of the 12 year old, also by the patient herself. In both cases, however, the parents had some concern about possible side effects of growth hormone treatment, in particular risks to existing kidney function. Concern about poor growth was outweighed by anxieties about possible outcome of treatment.

\section{Discussion}

The results from this cross sectional study do not confirm that most children with CRF and 
significant short stature show significant levels of concern about their growth failure when this is taken in the context of other aspects of their illness, treatment, and life stresses. Although growth was the second most frequently scored major worry after concern about the family, it was only a preoccupying concern for four $(28 \%)$ children. Of the children able to complete both scoring and ranking of concerns, the majority were adolescents, so that the lack of widespread, intense concern about growth was surprising. Our results highlight that parents have considerable worries about their children's future health and prospects and we found that one third acknowledged growth as an area of significant concern. Previous studies of renal patients have suggested that growth is a more major source of concern ${ }^{348}$ but these studies largely report anecdotal information and no systematic study of this area has previously been undertaken.

There are several possible issues to consider here. First, these young people are caught up in the complex demands of chronic illness, the treatment of which may intrude markedly upon their way of life and normal adolescent routines. It is perhaps not surprising that these youngsters have different concerns from otherwise healthy young people. Secondly, this group is more likely to be physically and emotionally immature than their healthy peers. This may result in many patients with CRF experiencing typical adolescent concerns rather later than their healthy counterparts. Some support to the view of a developmental perspective postponed in time is given by the finding of a correlation between increasing age and raised concern about growth, as well as a trend towards a higher ranking of growth among other concerns in the oldest children in the sample. Thirdly, we are aware that short stature is not always a negative experience for healthy adolescents. ${ }^{14}$ There may be ways that short stature is protective for young people with CRF, perhaps allowing the chronically sick child to be taken as younger than his age, and not faced with the demands for peer group functioning, independence and responsibility, which would otherwise be expected of him.

At interview we thought that there was a tendency for some children to deny difficulties and to minimise their concerns associated with illness, including growth. This may explain why ratings are lower for items which relate directly to the child than for the one item relating to other family members. The use of denial is recognised as adaptive in patients with chronic illness ${ }^{29}$ and this may be one method used by this group in coping. We therefore consider that it is important to use rank ordering as well as scoring when evaluating children's concerns, as it gives added opportunity for children who may have difficulty acknowledging their concerns.

Our study also highlighted the complicated, multifactorial problems which patients with CRF present to clinicians. We identified a group of transplant patients who were significantly smaller than other treatment groups. As we would have expected children to grow better after transplantation, it seems that this is a subgroup of children with CRF who have other handicaps, including growth failure. This observation reflects changes in the pattern of patients who are entering CRF programmes. There are now increasing numbers of younger and often multiply handicapped children ${ }^{30}$ resulting also in an increase in numbers with growth problems.

We were surprised at the proportion of children in this study who had learning difficulties $(30 \%)$; this was significantly higher than in previous studies conducted by this department. Greater attention may need to be paid in future to systematic cognitive assessment of the children; assumptions can no longer be made that standardised instruments can be employed as readily as heretofore. There is a need to repeat previous research into children's adjustment and behaviour. To date, however, it appears that parent reported levels of behaviour problems and difficulties in peer relationships are consistent with the results of previous studies of less impaired youngsters. ${ }^{15}$

Differences between the predominant concerns of parents and children were striking. Parents' prime concerns were about their child's future health and prospects while children were concerned about the effects of their illness on their family. Growth was the next most frequently reported major concern for both parents $(30 \%)$ and children $(28 \%)$. We have already considered a possible explanation for lower level of concerns in children. This may also explain our finding that there was no significant association between levels of parental and child concern about growth. A further explanation may be that parents and children assess the impact of short stature differently, as reported previously by Boulton et al. ${ }^{16}$ One clear implication for practice is that clinicians need to be alert to the possibility of differences in views between parents and children and of tension that might arise in relation to decision making and varying responses to treatment.

Parents and children demonstrated a low level of awareness about each other's worries. It is perhaps not surprising that children are unaware of their parents' concerns but parents' lack of awareness about their children's worries is more unexpected. It is well recognised among child psychiatric populations that parent and child reports differ significantly for 'internalising' symptoms such as depression, anxiety, and suicidality. ${ }^{31}$ It is therefore important that children and adolescents are given the opportunity to discuss their worries independently from their parents if a full assessment of their concerns is to be made. This study has identified a group of patients who are worried about the impact their illness has on their family, which is evidence of a stress which may often go unrecognised. It is important to acknowledge this with the children and to take their concerns into account when planning support for parents and families.

It is surprising that parents did not express more major concern about immediate issues 
surrounding treatment or behaviour, particularly given the number of children with high levels of behaviour symptoms reported in questionnaires $(30 \%)$. These findings should be interpreted within the context of the range of problems associated with the chronic illness. The importance of individual problems faced by children and parents may vary over time. Given the uncertain nature of their child's chronic illness, parents tend to adopt a longer term perspective.

Our semistructured interview was designed to tease out worries and relate them to current issues in a way that was not perceived as threatening or intrusive by families or clinicians. Overall there was agreement between both of the methods (scoring and ranking) that we used for assessing parent and child concerns. We believe that these may be useful tools for eliciting parental and child concerns. The findings should be interpreted in the context of difficulties experienced by parents and children in prioritising and discussing their various worries and how these may vary over time. We are also aware that this is a small sample and the methodology still awaits validation with other chronically sick populations. It is therefore appropriate to be cautious about generalising from our results.

We conclude that it is important to consider growth problems within the context of other issues relating to CRF. The study gives initial reassurance to clinicians who are recruiting patients for growth hormone treatment and who are anxious not to increase further the worries of a group of children and parents who are already burdened. Gaining a better understanding of the respective concerns of parents and children, however, may help to minimise any difficulties experienced by individuals who undergo growth hormone treatment. If we can increase growth in a majority of patients without increasing their concerns this must obviously be beneficial. In addition it may be helpful if we can support patients who do not respond well to treatment. A study of the longer term physical and psychological reactions to treatment may help to elucidate this. We found this group of patients with CRF to have multiple and complex problems and note that parents and children are often unaware of each other's main concerns. The study highlights the need to find ways of communicating with such children and the importance of involving both children and parents in discussion about their illness and treatment. Although children's worries may not always be severe enough to cause disturbance, a better understanding of their concerns may help clinicians in their management of the child and his treatment and help prevent major problems from developing.

We would like to thank the parents and children who took part in this study, Mrs S Marland for her secretarial help and Mrs S Hollis of the Department of Medical Computation, University of Manchester. This research would not have been possible without the generous financial support of Kabi Pharmacia. We are also very grateful to the following people without whose help and collaboration the study would not have been possible: Dr J Evans, Dr M Lewis, and Sister J Willock (Royal Manchester Children's Hospital); Dr D Milford, Mrs C Hawkins, and Dr L Winkley (Birmingham Children's Hospital); Dr L Rees, Dr H
Maxwell, Mrs S Madden, and Sister R O'Sullivan (Royal Free Hospital); Dr T Brocklebank and Sister C Pendlebury (St James's Hospital, Leeds).

1 Rees L, Rigden SPA, Ward GM. Chronic renal failure and growth. Arch Dis Child 1989; 64: 573-7.

2 Rigden SPA, Rees I, Chantler C. Growth and endocrine function in children with chronic renal failure. Acta Paediatr Scand (Suppl) 1990; 370: 20-6.

3 Grushkin CM, Korsch BM, Fine RN. The outlook for adolescents with chronic renal failure. Pediatr Clin North Am 1973; 20: 953-63.

4 Henning P, Tomlinson L, Rigden SPA, Haycock GB, Chantler C. Long term outcome of treatment of end stage renal failure. Arch Dis Child 1988; 63: 35-40.

5 Reynolds J, Morton M, Garralda ME, Postlethwaite RJ, Goh D. Psychosocial adjustment of adult survivors of a paediatric dialysis and transplant programme. Arch Dis Child 1993; 68: 104-10.

6 Morton M, Reynolds J, Garralda ME, et al. Psychiatric adjustment in end-stage renal disease: a follow up study of former paediatric patients. F Psychosom Res 1994; 38 : 293-303.

7 Reynolds JM, Garralda ME, Jameson RA, et al. Living with chronic renal failure. Child Care Health Dev 1986; 12: 401-7.

8 Poznanski EO, Miller E, Salguero C, Kelsh RC. Quality of life for long-term survivors of end stage renal disease. fAMA 1978; 239: 2343-7.

9 Eiser C. Children's understanding of medical procedures. The Practitioner 1985; 229: 371-3.

10 Garralda ME. Chronic physical illness and emotional disorder in children. Br f Psychiatry 1994; 164: 8-10.

11 Law CM. The disability of short stature. Arch Dis Child 1987; 62: 855-9.

2 Gordon M, Crouthamel C, Post EM, Richman N. Psychosocial aspects of constitutional short stature; social competence, behaviour problems, self-esteem and family functioning. 7 Pediatr 1982; 101: 477-80.

13 Voss LD, Bailey BJR, Mulligan J, et al. Short stature and school performance - the Wessex Growth Study. Acta Paediatr Scand (Suppl) 1991; 377: 29-31.

14 Sandberg DE, Brook AE, Campos SP. Short stature in middle childhood: a survey of psychosocial functioning in a clinic-referred sample. In: Stabler B, Underwood IF, eds. Growth, stature and adaptation Chapel Hill: eds. Growth, stature and adaptatio

15 Garralda ME, Jameson RA, Reynolds JM, Postlethwaite RJ. Psychiatric adjustment in children with chronic renal failure. F Child Psychol Psychiatry 1988; 29: 79-90.

16 Boulton TJC, Dunn SM, Quigley CA, et al. Perceptions of self and short stature effects of two years of growth hormone treatment. Acta Paediatr Scand (Suppl) 19.91; 377: 20-7.

17 Rotnem D, Cohen D, Hintz R, Genel M. Psychological sequelae of relative 'treatment failure' for children receiving human growth hormone replacement. $\mathcal{f} \mathrm{Am}$ Acad Child Psychiatry 1979; 18: 505-20.

18 Dean H, McTaggart TL, Fish DG, Friesen HG. The educational, vocational and marital status of growth hormone-deficient adults treated with growth hormone during childhood. Am $¥$ Dis Child 1985; 139: 1105-10.

19 Postlethwaite RJ, Reynolds JM, Wood AJ, Evans JHC, Lewis MA, Eminson DM. Recruiting patients to clinical Lewis MA, Eminson DM. Recruiting patients to clinical in renal failure. Arch Dis Child 1995; 73: 30-5.

20 Reynolds JM, Garralda ME, Jameson RA, Postlethwaite RJ. How parents and families cope with chronic renal failure. Arch Dis Child 1988; 63: 821-6.

21 Goldberg D, Hillier VF. A scaled version of the general health questionnaire. Psychol Med 1979; 9: 139-45.

22 Rutter M, Tizard J, Whitmore $\mathrm{K}$, eds. Education, health and behaviour. London: Longmans, 1970.

23 Richman N, Stevenson J, Graham P. Pre-school to school; a behavioural study. London: Academic Press, 1982.

24 Goodyer IM, Wright C. Recent friendships in anxious and depressed schoolage children. Psychol Med 1989; 19: 165-74.

25 Harter $S$. The perceived competence scale for children. Child Dev 1982; 53: 87-97.

26 Costello EJ, Angold A. Scales to assess child and adolescent depression; checklists, screens and nets. $\mathcal{F}$ Am Acad Child Psychiatry 1988; 27: 726-34.

27 Wood A, Kroll L, Moore A, Harrington R. Properties of the moods and feelings questionnaire in adolescent psychiatric outpatients: a research note. $\mathcal{f}$ Child Psychol Psychiatry 1995; 36: 327-34.

28 Hoare $P$, Elton R, Greer A, Kerley S. The modification and standardisation of the Harter self-esteem questionnaire with Scottish school children. European Child and Adolescent psychiatry 1993; 2: 19-33.

29 Taylor D, Eminson DM. Psychological aspects of chronic physical sickness. In: Rutter M, Taylor E, Hersov L, eds. Child and adolescent psychiatry, modern approaches. 3rd Ed. Oxford: Blackwell Scientific Publications, 1994: 737-48.

30 Rizzoni G, Ehrich JHH, Brunner FP, et al. Combined report on regular dialysis and transplantation of children in Europe, 1988. Nephrol Dial Transplant 1989; 4 (suppl 4): $31-40$.

31 Angold A, Weissman MM, John $\mathrm{K}$, et al. Parent and child reports of depressive symptoms in children at low and high risk of depression. F Child Psychol Psychiatry 1987; 28: 901-15. 